\title{
DEL SENTIDO DE LA BIOÉTICA
}

\author{
Jean Ladrière \\ Matemático y Filósofo \\ Profesor Emérito de la Universidad Católica de Lovaina, Bélgica
}




\section{DEL SENTIDO DE LA BIOÉTICA}

\section{Jean Ladrière}

\section{Resumen}

En el texto que sigue Jean Ladriére reflexiona sobre el sentido y la significación de la bioética en el contexto de lo que hoy se denomina el crecimiento de las "éticas aplicadas". Este contexto le conduce, desde las primeras líneas, a rehusar la idea según la cual las "éticas regionales" se limitarían a traducir -en el ámbito de situaciones concretas- principios generales, puesto que ello sería equivalente a desconocer la creatividad, las posibilidades innovadoras y los riesgos que conlleva la acción en su determinación constante de la existencia.

Estableciendo la necesidad de inaugurar la reflexión sobre el tema propuesto desde el espacio que ocupa y legitima el accionar de la bioética, intenta mostrar la complicidad que reúne la bioética con la ética y desentrañar la manera específica como la bioética responde a la exigencia de producción de normas, que se desprenden, en particular, de los desafios de la acción humana y tecnocientífica.

La argumentación que Jean Ladrière despliega, abarca de manera resumida, temáticas abordadas a lo largo de su obra y que pueden aparecer al lector desprevenido como demasiado herméticas. La temática de la tecnociencia fue abordada por Jean Ladrière en su libro Les enjeux de la rationalité (1977) y otras múltiples publicaciones; la problemática de la existencia y su relación con el sentido en L'articulation du sens (1971 para el tomo 1,1985 para el tomo 11), y el tema de la ética y de la dimensión ética de la existencia en L'éthique dans l'univers de la rationalité (1997).

Conviene agregar que como traductor de este texto intenté utilizar las ediciones en castellano de algunos autores citados, pero frente a diferencias respecto de ciertos términos -que dan cuenta de diferencias de interpretación-, opté por traducir directamente del texto de Jean Ladrière.

Palabras clave: Ética, Dimensión ética de la existencia, Bioética, Norma, Normatividad, Acción, Existencia.

$$
\text { Sergio Zorrilla - Traductor }
$$

\section{Resumo}

No presente texto, Jean Ladrière faz uma reflexão sobre o significado da bioética no contexto do que hoje se denomina o crescimento das "éticas aplicadas". Já nas primeiras considerações recusase a aceitar a idéia de que as "éticas regionais" se limitariam a traduzir, no âmbito de situações concretas princípios gerais, pois isto seria o mesmo que desconhecer a criatividade, as possibilidades inovadoras e os riscos que implicam a ação em sua constante determinação sobre a existência.

Estabelece a necessidade de iniciar a reflexão sobre o tema proposto desde o espaço que ocupa e legitima o agir bioético. Pretende mostrar a cumplicidade que aproxima a bioética à ética e averiguar a maneira como a bioética responde à exigência de produção de normas, que se afasta, em particular, dos desafios da ação humana e tecnocientífica.

A argumentação que Jean Ladrière apresenta, abarca de maneira sucinta, temáticas abordadas por toda sua obra e que podem parecer ao leitor menos avisado como demasiado herméticas. A temática sobre a tecnociência foi abordada pelo autor em seu livro Les enjeux de la rationalité (1977) e em inúmeras outras publicações. A problemática da existência e sua relação com o sentido em L'articulation du sens (1971 para o volume I, 1985 para o volume II).O tema da ética e da dimensão ética da existência em L'éthique dans l'univers de la rationalité (1997).

Convém acrescentar que como tradutor do presente texto tentei utilizar as edições em espanhol de alguns autores, mas diante de diferentes interpretações, optei por traduzir diretamente do texto original de Jean Ladrière.

Palavras chaves: Ética, Dimensão ética da existência, Bioética, Norma, Normatividade, Ação, Existência.

Sergio Zorrilla - Tradutor 


\section{Abstract}

The following text shows us the reflections made by Jean Ladrière concerning the sense and meaning of bioethics in the context of what is known today as the growth of "applied ethics".

From the first considerations he refuses accepting the idea that "regional ethics" limits itself to translate -into the sphere of concrete situations- general principles, since this would be equivalent to ignore creativity, innovative possibilities and the risks involved in the action in its permanent determination of existence.

Establishing the need of inaugurating reflections concerning proposed themes -from the space filled and legitimized by bioethical drivehe attempts to show the complicity between bioethics and ethics, as well as to puzzle out the specific way in which bioethics respond to the demands of producing regulations, that in particular are consequence of the challenges of human and techno-scientific actioning.

Jean Lardrière's argumentation briefly explains issues addressed throughout his research and which may seem too hermetic to the unprepared reader.

The subject of techno-science was analyzed by Jean Ladrière in his book Les enjeux de la rationalite (1977) and in many other publications; the issue of existence and its relationship with the sense in L'articulation du sens (1971, volume $1 ; 1985$, volume 2 ), and the topic of ethics and the ethical dimension of existence in L'ethique dans l'univers de la rationalité (1997).

It is relevant pointing out that as translator of this text, I tried to use Spanish issues of some of the authors quoted but in front of differences related to certain terms -showing disparity of interpretation-I decided to translate them directly from Jean Ladrière's text.

Key words: Ethics, Ethical dimension of existence, Bioethics, Rule, Regulations, Action, Existence.

Sergio Zorrilla -Translator

\section{Résumé}

Dans le texte qui suit, Jean Ladrière fait une réflexion sur le sens et le significat de la bioéthique dans le contexte de ce qu'on appelle aujourd'hui la croissance des "éthiques appliquées". Ce contexte conduit, dès les premières lignes, à refuser l'idée selon laquelle les "éthiques régionales" se limiteraient à traduire, dans le cadre des situations concrètes, des principes généraux, du fait que ca serait équivalent à ne pas reconnaître la créativité, les possibilités innovatrices et les risques portés par l'action dans sa détermination permanente de l'existence.

En établissant la nécessité d'innaugurer la réflexion sur le sujet proposé, à partir de l'espace que occupe et qui légitime le mode d'action de la bioéthique, l'auteur essaie de montrer la complicité qui unit la bioéthique à l'éthique et de degager la facon spécifique dont la bioéthique répond à l'exigence decréation de normes qui, en particulier, se detachent des défits de l'action humaine et technoscientifique.

L'argument que Jean Ladrière deploie, comprend, de facon résumée, des sujets abordés tout au long de son oeuvre et qui peuvent paraitre trop herméthiques au lecteur pris au dépourvu. La thématique de la thechnoscience fut abordée par Jean Ladrière dans son livre Les enjeux de la rationalité (1977) entre autres publications; La problématique de l'existence et sa relation avec le sens dans L'articulation du sens (1971 pour le volume $n^{\circ} 1,1985$ pour le volume $n^{\circ} 2$ ), et le sujet de l'éthique et de la dimension éthique de l'existence dans L'éthique dans l'univers de la rationalité (1997).

On peut ajouter que, en tant que traducteur de ce texte, j'ai essayé d'utiliser les éditions en espagnol de certains auteurs cités, mais face à des différences concernant certains termes qui pouraient provoquer des différences d'interprétation, j'ai décidé de traduire directement du texte de Jean Ladrière.

Mots clés: Éthique, Dimension éthique de l'existence, Bioéthique, Norme, Normativité, Action, Existence.

Sergio Zorrilla - Traducteur 
Hoy en día se habla a menudo de la "ética aplicada" para designar socialmente los lugares de interacción entre la preocupación ética y los diferentes ámbitos de la práctica. La bioética es considerada como uno de esos espacios, caracterizada por el término "bio", que podría evocar vida en general, aunque concierne mayoritariamente a la vida humana. Sin embargo, esta manera de hablar parece indicar que existe una "ética fundamental" o una "ética teórica", que establece los principios generales válidos para todas las prácticas humanas y que, por otro lado, existen "éticas regionales" que, de cierta manera, traducen estos principios generales en las situaciones concretas y particulares de las diversas "regiones" de la práctica.

Este esquema -que no compartimos- se parece mucho al utilizado en las prácticas operatorias, en las cuales a los datos se les aplica un programa para resolver un problema. Para ello el programa posee lo que se denomina "parámetros", que son tipos de magnitudes que se pueden establecer arbitrariamente. En suma, se trata solamente de una forma de operación. (Así la regla de la división matemática es un programa que establece formalmente como es posible la división de un número por otro). La opción de los valores determinados por los parámetros "llena de contenido" esta forma y permite una operación concreta.

El esquema anterior es un caso particular de un procedimiento descendente que consiste en transitar de un principio a sus consecuencias y cuyo modelo más apropiado es, sin duda alguna, la deducción lógica. Pero es lícito preguntarse si la reflexión ética no se refiere, más específicamente, a un tipo de procedimiento ascendente, que parte de los datos concretos para progresar hacia sus condiciones de existencia. La naturaleza de este tipo de procedimiento no se relaciona con la implicación; al contrario, con la des-implicación, que trata de desprender de lo dado concretamente lo que se encuentra de alguna manera envuelto en el modo de ser de lo dado. En el caso de la ética este procedimiento regresivo permite despren- der de las circunstancias, siempre particulares de la acción, los elementos normativos que permiten juzgarlas $u$ orientarse en función de lo que ellas sugieren. Esta es la construcción de normas. Pero las mismas normas remiten a lo que les confiere su normatividad. De esta manera la regresión es orientada a desarrollarse en la dirección de lo que es constitutivo del orden ético. Es lo que puede llamarse la explicitación del fundamento de la ética. La lectura regresiva de la acción puede volver posible una lectura retrospectiva, que permite elucidar la acción en el sentido de las normas que la orientan y elucidar las normas a partir de la naturaleza de su fundamento.

Una reflexión sobre el sentido de la bioética debe originarse en el espacio particular que ella interroga, lo que se relaciona con un procedimiento regresivo y, enseguida, preguntarse sobre lo que la constituye como "ética" y sobre la forma específica que adopta para ella la determinación de normas. Estas dos tareas se conectan con la lectura retrospectiva que hemos evocado más arriba: la investigación sobre lo que constituye la ética debe clarificar el procedimiento de construcción de normas desarrollado por la bioética y el cuestionamiento sobre la determinación de las normas debe clarificar los procedimientos concretos de la bioética, entendida como forma específica de acción.

\section{El lugar de cuestionamiento de la bioética}

La bioética, tal como hoy se presenta, no es ni un saber (incluso si abarca aspectos cognitivos), ni una forma particular de experticia (incluso si posee una capacidad de experiencia y de intervención), ni una deontología (incluso si posee aspectos normativos). Es una práctica racional muy específica que pone en movimiento, al mismo tiempo, un saber, una experiencia y una competencia normativa, en un contexto particular del accionar que es definido por el prefijo "bio".

Podríamos caracterizarla de mejor mane- 
ra diciendo que es una instancia de juicio, aunque precisando que se trata de un juicio práctico, que se ejerce en circunstancias concretas y al que se asigna una finalidad práctica a través de diferentes formas de institucionalización. De esta manera, la bioética constituye una práctica de segundo orden, operando sobre prácticas de primer orden, en contacto directo con las determinaciones concretas de la acción en el ámbito de las bases biológicas de la existencia humana.

La expresión "bases biológicas" de la existencia humana debe ser tomada en un sentido muy amplio. Existe un núcleo de aspectos que interesan a la bioética que incumben directamente los soportes somáticos de la existencia humana, por medio de la investigación o de diferentes prácticas clínicas, que ponen en juego directamente estos soportes. En este dominio, la bioética, se entrecruza ampliamente con la ética médica. Aunque, en la medida que la investigación sobre lo vivo se profundiza, el campo de cuestionamiento de la bioética se amplía. Y si la existencia humana es en definitiva el desafío esencial, es la vida misma en toda su extensión que se encuentra cuestionada.

La instauración de esta práctica de juicio y su institucionalización, que es en los hechos un acto político, plantea dos preguntas mayores desde el punto de vista de la reflexión sobre el sentido de la bioética. Por un lado, ¿cuál es el proceso histórico que ha creado este nuevo campo de la práctica constituido por la bioética? y, por otro lado, ¿cuál es la perspectiva específica que define esta práctica?

A la primera de estas preguntas debemos responder evocando el desarrollo científico acerca del fenómeno de la "vida" y las repercusiones de este desarrollo en las prácticas médicas (entendidas en un sentido amplio), así como en el campo más vasto de lo designado por el concepto de "salud pública".

Es sorprendente que la biología como ciencia haya permanecido durante tanto tiempo como una disciplina esencialmente descriptiva, en contraste con el desarrollo teórico im- presionante de las ciencias físicas. Ciertamente, desde el siglo XIX, la biología se había dado un estatuto científico, en un sentido estricto, aplicando sistemáticamente los esquemas de la causalidad. Pero los medios de observación y experimentales no permitían descender más allá de un cierto nivel de organización. Y la medicina, de su lado, sólo podía disponer de medios de investigación que permanecían al nivel de lo macroscópico. Sin embargo, desde la mitad del siglo XX, la ciencia de lo vivo dio un paso absolutamente decisivo para la comprensión del fenómeno de la "vida" al desentrañar -más allá incluso del nivel celular-el nivel de los constituyentes químicos de la vida y de sus dinámicas propias. Sobre esta base ha sido posible descubrir los constituyentes moleculares de los genes. La secuencia del genoma humano es la consecuencia lógica de esos descubrimientos. A partir de la información adquirida se abren posibilidades absolutamente inéditas que resume la expresión "manipulaciones genéticas". Esta capacidad de descender al nivel molecular significa, desde un punto de vista práctico, una verdadera revolución de la medicina. Y desde ahora se anuncia un gran debate político a propósito del control de la información genética. Sin embargo, la problemática genética es sólo un sector de la problemática biológica en general. Las posibilidades de intervención en el dominio de la procreación o las técnicas de trasplantación de órganos son otros ejemplos sorprendentes del tipo de situación creado por la transformación de la ciencia biológica después de la segunda mitad del siglo XX.

Los progresos en el orden del saber en este campo, se traducen, sin embargo, casi inmediatamente en la creación de nuevas capacidades de intervención. El sentido general de estas intervenciones es de reemplazar los procesos "naturales" por procesos artificiales. Es lo que se percibe, por ejemplo, en el caso de una técnica médica como la fecundación in vitro. Es necesario reconocer que la finalidad de tal operación permanece en el marco del proceso natural correspondiente. La sustitución es sólo 
parcial. Mas, en el caso de la clonación nos enfrentamos a la creación pura y simple de una posibilidad inédita, que puede transformar la relación de descendencia. En un sentido bastante evidente, un clon es un ser artificial.

La distinción entre lo artificial y lo natural puede ser expresado a través de un criterio aristotélico: el ente natural es un ente que es "por naturaleza" o "en virtud de la naturaleza" (es decir, que proviene - por un proceso intrínseco de engendramiento- de un ente de la misma especie), mientras que un ente artificial es un ser que es "en virtud del arte", es decir, de una práctica propiamente humana. Retomando los términos griegos, se podría decir que el ente natural tiene su origen en la génesis, mientras que el ente artificial tiene su origen en la poiesis.

Sin embargo, esta evolución de las ciencias de la vida y de las prácticas que se desprenden son parte de un proceso global que es una de las manifestaciones más destacadas de la "modernidad", es decir, del nacimiento y desarrollo de lo que se llama tecnociencia. Esta expresión coloca el acento sobre la estrecha interdependencia que se instaura en la época contemporánea entre la investigación científica y la innovación tecnológica. Por un lado, los logros en el orden del conocimiento científico -que son de tipo ideal-son proyectados en las realizaciones exteriores de orden material, cuyo mejor ejemplo es el autómata "inteligente". Por otro lado, la tecnología procura a la investigación científica los instrumentos que le permiten explorar los dominios de la realidad cósmica que son inabordables desde la percepción, como las nebulosas cercanas o las partículas elementales.

Desde un cierto punto de vista, la tecnociencia es simplemente el conjunto de prácticas que se desprenden de la idea de ciencia o de tecnología, asociadas al conjunto de artefactos sobre los cuales se sostienen estas prácticas (aparatos científicos y máquinas de todo tipo). Sin embargo, esta manera de ver las cosas reduce la tecnociencia a una suma de modelos de acción y de objetos artificiales. Olvi- damos que el carácter más esencial de la tecnociencia es su capacidad de constituir un universo que se encuentra en interacción con el universo natural, pero que se construye como una totalidad sui generis, cada vez más autónomo en relación al mundo natural, imponiendo de manera casi obligatoria sus propias leyes de funcionamiento a la acción humana. En realidad, es la acción humana que engendra la tecnociencia, pero creándola, se convierte deliberadamente dependiente de las posibilidades que ésta le ofrece, aunque también, de las posibilidades que se le abren y de las limitaciones que ello implica.

Así, es impresionante constatar como en pocos años la tecnología de las computadoras ha transformado - sin haberlo querido de forma explícita- las interrelaciones de la vida profesional e incluso las modalidades más elementales del intercambio en la vida cotidiana. Conviene agregar que el universo tecnocientífico no es simplemente una extensión del universo natural. Es otra realidad, que tiene su propio sistema de significaciones y que se encuentra animada por una dinámica en la cual la acción deviene simple mediación de un proceso que sólo domina de forma parcial. La tecnociencia constituye un universo que posee unidad y autonomía, poniendo en juego de forma implícita - a causa de su funcionamiento- una cierta visión del mundo, que ejerce un efecto de inducción sobre sus creadores y los utilizadores. Esta visión del mundo se desprende de su componente cognitivo, es decir, la ciencia. Los otros componentes de la tecnociencia sólo son la proyección de esta visión en los aparatos de todo tipo que constituyen los componentes propiamente tecnológicos.

La visión científica del mundo no es "natural", como lo es la visión perceptiva. Se apoya en un proceso de objetivación que es, al mismo tiempo, un proceso de instauración. Este proceso pone en juego un doble postulado, que corresponde a una doble restricción. La adopción de este doble postulado tiene el carácter de una decisión libre, estableciendo unas ciertas limitaciones que el "pensamiento científi- 
co" asume como una obligación. Es claro, por un lado, que sólo serán considerados como pertinentes los aspectos de la realidad que pueden ser reconocidos como independientes de cualquier intervención de la subjetividad. Este postulado de objetividad, que se encuentra en la base de la distinción entre cualidades primarias y cualidades secundarias, es establecido en la época en que se constituye la física moderna.

También es claro, por otro lado, que sólo serán considerados los objetos y propiedades susceptibles de conectarse directa o indirectamente con datos estrictamente empíricos. Este postulado de empirismo se encuentra en el origen de uno de los principios en que se expresa el empirismo lógico, que lo consideraba como un supuesto fundamental del pensamiento científico. Carnap ha propuesto una formulación en términos de exigencias válidas para el lenguaje científico:

Como empiristas exigimos que el lenguaje de la ciencia se restrinja de cierta manera; exigimos que los predicados descriptivos y por lo tanto, también las proposiciones sintéticas, sólo sean admitidas bajo la condición de que tengan alguna conexión con las observaciones posibles, conexión que debe ser caracterizada de forma conveniente (1).

La restricción operada por estos dos postulados significa negativamente el abandono del mundo percibido y de lo que se revela en la intuición. Pero positivamente, significa la apertura a un nuevo campo de experiencia y de pensamiento. En realidad, lo que emerge es un campo de posibilidades y más exactamente, de posibilidades de construcción. El procedimiento científico construye los objetos de los que se ocupa y construye las situaciones experimentales en las cuales sus hipótesis pueden ser verificadas. Las significaciones que surgen gracias al universo que este procedimiento engendra se sitúan en el entrecruzamiento de lo que permiten ver estos modelos, de preferencia de forma matemática, que sirven en sus investigaciones y en las operaciones concretas a través de las cuales este procedimiento formula proposiciones que reciben una materialización creciente. Pero, conviene agregar, que estas significaciones son solamente intrínsecas: su poder significante vale en el supuesto de decisiones iniciales que han instaurado la práctica científica "moderna".

El hecho que los objetos y propiedades del universo científico puedan ser de alguna manera manifestados por dispositivos experimentales confiere a este universo una propiedad global que podríamos denominar su capacidad de proyección. La física, por ejemplo, construye el concepto abstracto de "campo electromagnético", cuyo referente es un cierto objeto del universo científico y propone un formalismo matemático que representa el comportamiento de este objeto. En ciertos montajes experimentales se pueden verificar las previsiones hechas sobre la base de este formalismo. Se podría decir que dicho montaje es una proyección de lo que se muestra abstractamente en el formalismo. $\mathrm{Y}$ de manera general se podría decir que el sentido del concepto "campo electromagnético" es procurado por el formalismo del electromagnetismo, además de todas sus otras proyecciones. La ciencia del electromagnetismo utiliza algunas de estas proyecciones con un objetivo solamente epistemológico, para procurar una base empírica a sus representaciones teóricas. Pero nada impide realizar, por ejemplo, proyecciones que puedan servir a fines de tipo "utilitario" para trasmitir informaciones rápidamente . La proyección es en sí independiente de las finalidades en vista de las cuales se la utiliza. Esta operación de proyección concluye la transición de lo que es puramente científico a lo que es científico-técnico, es decir, el paso del universo científico al universo tecnológico.

Sin embargo, la ciencia y la técnica no se hacen solas. Los procesos de construcción y de proyección son amplificados por la acción, como lo muestra la introducción del concepto de fin: la acción es un comportamiento que persigue explícitamente fines sobre la base de 
motivaciones previamente evaluadas. Toda acción es un proceso que se apoya sobre una situación dada, intentando transformarla en una nueva situación, adecuada a la finalidad propuesta. La construcción y la proyección son formas de acción. Proyectando en la realidad empírica ciertas representaciones que pertenecen al universo científico, la acción permite la existencia de situaciones objetivas, que son situaciones inéditas y que provocan su "perplejidad".

La posibilidad, por ejemplo, de la clonación humana-facilitada por los desarrollos de la genética, así sea en un largo período- permite evocar como posible, en principio, una situación totalmente "fuera de la naturaleza", cuya posibilidad no es segura que sea deseable. Pero, ¿cuál es el significado de la reserva emitida? Una situación realizada efectivamente o anunciada como posible sobre la base de la tecnociencia puede plantear problemas que son de naturaleza técnica o científica y que reenvían al proceso que la ha creado. En esta perspectiva el sentido de la situación se desprende de su inscripción al universo técnico-científico. El abanico de posibilidades que la tecnociencia abre puede ser considerado como dado, con la misma evidencia con que ella misma existe. Pero la "perplejidad" que embarga la acción no se reduce solamente a una preocupación técnica. Esta es, en un primer momento, una especie de intuición que anuncia el comienzo de un juicio. A través de ella se plantea una cuestión que no es de orden técnico. En los hechos, la duda que remueve la acción es una puesta en suspenso del universo tecnocientífico, de sus significaciones, de sus evidencias y por lo tanto, de su inserción en otra dimensión.

El estado de "perplejidad" en el cual la acción se instala es la manifestación de la referencia a un juicio posible e indica la presencia de un punto de vista normativo. Existe, tanto en la ciencia como en la técnica, un aspecto normativo y éste es determinante. El procedimiento científico se impone criterios estrictos de cientificismo, que son garantes de la vali- dez de sus proposiciones. E incluso el procedimiento técnico se impone también criterios estrictos de eficacia que son los garantes de la fiabilidad de sus resultados. Pero estos criterios, que en los dos casos son interpretables como directivas para la acción, permanecen estrechamente referidos a las propias estrategias de la tecnociencia. La normatividad implícita-que inspira el cuestionamiento respecto de lo inédito de ciertas situaciones-se desprende de una perspectiva que no pone en duda el valor verdadero de una proposición o la eficacia de una técnica, sino que la legitimidad de una acción.

Lo que se expresa en la perplejidad es una preocupación que proviene de la razón práctica, en el sentido de Kant, es decir, de la razón que apunta hacia las finalidades más altas de la acción, lo que Kant llama "la instauración de un mundo moral". La preocupación de la razón práctica no se reduce a la razón teórica, que reflexiona con el fin de adaptar sus hipótesis a las obligaciones que se desprenden de las observaciones disponibles, ni tampoco a la razón calculadora, que reflexiona sobre la mejor adecuación de los medios disponibles en relación con los fines. Se trata de una preocupación que moviliza la razón en torno a sí misma, no sólo porque se encuentra comprometida con tal o cual situación; a través de dicho compromiso la razón se pone a sí misma en juego, en el marco y la perspectiva de su calidad esencial. En la preocupación de la razón práctica se anuncia la dimensión ética de la acción. La acción que, en lo concreto de la situación, deviene consciente de la dimensión y desafío que representa para sí misma, se convierte en razón reflexiva. La acción a partir de su "perplejidad" busca reposicionarse frente a las exigencias que surgen del hecho que ella es razón práctica.

Aquí se descubre el lugar propio de la bioética y se anuncia el proceso regresivo que debe conducir la preocupación bioética hacia lo que funda su normatividad inmanente. El lugar propio de la bioética, desde donde se instituye, es la situación, en la medida que ésta pone 
en movimiento -directamente o través de diversas mediaciones- los fundamentos biológicos de la existencia humana y también en la medida en que la razón reflexiva descubre la eticidad, es decir, lo que plantea problemas desde el punto de vista de su relación con la dimensión ética de la acción. Dos condiciones intervienen por lo tanto en esta determinación: el contenido de la situación -particularizada por medio de conceptos que se desprenden de la tecnociencia- y la perspectiva que es considerada por la razón reflexiva, perspectiva que es caracterizada como "ética" según un sentido que debe ser elucidado por un análisis regresivo. Conviene por lo tanto, en la perspectiva anunciada, precisar lo que es la dimensión ética y en particular examinar como ella puede ser fuente de normatividad. Será necesario enseguida establecer ciertas precisiones sobre la determinación de normas. Sobre estas bases se podrá volver, en un camino retrospectivo, sobre la acción como lugar de emergencia y materialización de esta normatividad.

\section{La dimensión ética de la acción}

La presencia en la dinámica de la acción de una normatividad intrínseca que la concierne totalmente, y no sólo en tal o cual tipo de comportamiento, sugiere que esta normatividad no es local o periférica sino que pertenece a la constitución misma de la acción. Es esta sugerencia que intenta explicitar el término "dimensión", que utiliza una metáfora que proviene del campo de la geometría.

Podemos procurarnos una representación de un objeto con tres dimensiones relacionándolo con un sistema de tres ejes y construyendo su imagen según cada uno de estos ejes. Se obtiene entonces una especie de representación simplificada del objeto, en tres figuras, a partir de las cuales es siempre posible volver al objeto como tal, reuniendo en el espacio a tres dimensiones, las tres imágenes a dos dimensiones dadas. Las figuras a dos dimensiones son "proyecciones" del objeto según cada uno de los ejes. Cada proyección da una vista parcial del objeto, a pesar de que refleja bien la totalidad del objeto, según la perspectiva definida.

Hablando de la ética como una "dimensión" intentamos indicar que es una determinación que afecta la cosa real, la acción en su totalidad y, sin embargo, sólo la afecta según una cierta perspectiva. La idea es que la acción, considerada plenamente, constituye de alguna manera la reunión en una visión única de todas sus dimensiones. Pero si la ética es una dimensión, ella afecta la acción y por consecuencia cada una de sus otras dimensiones. Una "dimensión" no existe aislada. Cada una de las dimensiones de la acción define una perspectiva que puede ser interrogada y cuestionada. Es necesario precisar lo que constituye la dimensión calificada como "ética".

Para comenzar es necesario relacionar la acción con su espacio propio de manifestación. La acción no es un ente por sí mismo, es una de las manifestaciones esenciales del ser humano concreto, determinación particular del modo de ser del existente humano. Este término expresa bien -sobre todo a través del prefijo "ex"- el estatuto ontológico de un existente que es esencialmente dinamismo, salida fuera de sí mismo, apertura al mundo, a otro, a sí mismo, al corazón más secreto de la realidad. Si la acción es una determinación particular de la existencia, su estructura debe reflejar la estructura de la existencia, lo que nos permite conectar ésta con lo que se devela en la acción. Si la ética es una dimensión de la acción es porque ella es una dimensión de la existencia. La ética afecta la acción en la medida que inscribe a través de ella la normatividad específica a la cual remite el término "ética". Pero afecta la existencia de manera más radical: la ética es una dimensión porque traduce en exigencia la estructura misma de la existencia.

La existencia es una don, no se elige, se descubre en un cierto lugar, en un cierto tiempo, ligada a condiciones que se imponen de manera inevitable. La existencia se encuentra entonces marcada por una contingencia radi- 
cal. En cierto sentido, su ser se encuentra completamente establecido de antemano y sólo puede ser lo que efectivamente es. Pero, al mismo tiempo, la existencia se encuentra como separada de su ser, como carencia constante de su ser. En su ser mismo se encuentra inscrita una distancia que se reinstaura a cada paso; entre lo que ella ha llegado a ser y lo que es siempre llamada a ser. Pero esta fractura interior no es un estado, es la condición estructural que vuelve posible el dinamismo que la caracteriza. La existencia constantemente se vive como el esfuerzo siempre renovado de superar la escisión que la separa de sí misma, de reconciliarse, accediendo a la verdad de su ser. Si la existencia es un don no es posible entenderla como lo que se encuentra desde siempre realizado, sino que al contrario como aquello que se encuentra en camino de su propia realización. Su ser dado es solamente la potencialidad de un estado provisional, atravesado por el deseo que conduce la existencia hacia su ser realizado.

Es a partir de sí misma que la existencia es llamada a reunirse en la autenticidad de su ser. Es dada a sí misma, pero más bien como confiada a sí misma. De esta manera, es definida por la tarea de procurarse a sí misma, a través de su propia iniciativa, la determinación que le falta a su ser. El camino de su propia determinación y realización es la acción.

Existe en la acción una condición generadora de efectos: es por esencia intervención en el curso de las cosas -incluso de manera no visible - y gracias a esta capacidad, adquiere su concreción. Para intervenir, la acción debe someterse a los límites que se desprenden de la condición general de contingencia que se impone a la existencia. Estos límites definen lo que se puede llamar la situación. Es asumiendo la situación que la acción es capaz de inscribir su registro en el mundo. Lo que de un cierto punto de vista es limitación, en realidad es, desde el punto de vista de lo que se realiza, lo que confiere a la acción el poder de agregar nuevas determinaciones a la realidad constituida. Lo que la acción produce, en el frag- mento del mundo que le es accesible, repercute necesariamente sobre la existencia: ésta, gracias a los efectos provocados por la acción, se confiere nuevas determinaciones que contribuyen a dibujar su trayectoria.

Como la acción es condicionada, su efecto es necesariamente local, particular, contingente como la misma existencia. Si ella es capaz de modificar la situación, introduciendo nuevas determinaciones, es porque no se encuentra sujeta a la particularidad en que opera: insertándose completamente en el presente, apunta hacia un horizonte que se encuentra más allá de cualquier particularismo; horizonte que se manifiesta como exigencia/condición al que la acción debe moldearse. Pero ésta no es una condición antecedente, como aquellas que aseguran los efectos de la acción, es una condición que se inscribe en el orden de un telos (un término dotado de finalidad), telos que, en el ser presente de la existencia, explicitado por la acción, se expresa como una solicitud provocadora de su ser por venir. El sentido de la acción es precisamente la relación que se instituye con este término, situado más allá de lo que se está realizando, que sería como la figura realizada de lo que la acción apunta incesantemente.

Como la acción es la misma existencia, considerada como fuente de iniciativa, la estructura de la acción -mediación entre las situaciones y el telos que induce la existencia desde su ser por venir- es también la estructura de la existencia. En esta estructura se manifiesta su temporalidad, que define su estatuto ontológico. La existencia efectiva es lo que en ella se encuentra inscrito como realizado, la existencia como extendida hacia su ser por venir, es el eco en ella de lo que la orienta y la organiza. Y el momento de la acción es el presente como transición, paso, donde lo ya realizado es asumido en la perspectiva representada por la realización integral de la existencia.

Esta estructura, que es de orden formal, explicita dos caracteres esenciales que ponen en juego el destino real de la existencia. Por un lado la perspectiva que sostiene la acción 
no es solamente la relación con un término que debe aparecer. Es la expresión de una exigencia constitutiva, inscrita en el ser de la existencia y explicitada por el evidenciamiento de su estructura. Por otro lado, a través de esta exigencia la existencia es instituida como responsable de sí misma. La exigencia no es una limitación, es un mandato o un llamado, a través del cual el ser por venir exige al ser presente asumir, en su acción, la tarea de reunírsele y a través de ello alcanzar su realización. La existencia es llamada a devenir portadora de lo que acontece con su ser, ratificando por medio de lo que hace la generación de todas las condiciones que deben asegurar su realización plena.

El hecho que la existencia se constituya como responsable de sí misma implica que posee un poder adecuado al nivel de esta exigencia. En términos kantianos se podría decir que este poder es la capacidad de darse a sí misma su propia ley, es decir, su autonomía. Esta expresión podría sugerir que la existencia organiza su acción de manera arbitraria, dándose máximas que no tienen otro fundamente que su propia voluntad. Pero, la autonomía significa que la ley -que expresa la exigencia que vuelve la existencia responsablees una ley interior, en la que la existencia reconoce los imperativos que condicionan la realización de su ser.

La realización de la existencia es el despliegue integral de su ser. Su estatuto como ser es aquel de un existente que conlleva en sí mismo, en su existencia, la responsabilidad de sí mismo, de un existente que tiene la tarea de vivir según lo que es exigido por el estatuto del ser. Lo que caracteriza a un existente responsable de sí mismo es la autonomía o aun, la libertad. Vivir según la exigencia de dicho estatuto de ser es, por lo tanto, vivir según lo exigido por el estatuto de un ser libre.

La ley interior que es llamada a darse la existencia es una ley en la cual la libertad se procura las condiciones de su existencia. Y estas condiciones son aquellas que deben asegurar la realización de la existencia. La liber- tad, dándose como ley el respeto de estas condiciones, asume las exigencias que se desprenden del estatuto del ser de un existente responsable de sí mismo, dicho de otra manera, de un existente caracterizado por la libertad y en definitiva por la libertad consigo mismo. De esta manera la libertad es equivalente a asumir libremente su propio estatuto de ser. Pero la libertad se vive en un devenir, en el que sus exigencias deben encontrar las determinaciones concretas que aseguren su porvenir.

La exigencia que la existencia reconoce en su propio ser como imposición es, en suma, la exigencia de su realización, es decir, la exigencia de devenir lo que ella es como expresión de un llamado de sí misma o, dicho de otra manera, como búsqueda para alcanzar su ser auténtico. Pero, ¿cuál es su ser auténtico? Podemos sugerir que es el estatuto de un existente caracterizado por la libertad.

Esta es, sin embargo, una determinación que permanece formal. La cuestión que se plantea se relaciona con su determinación concreta. La existencia se encuentra en camino hacia sí misma y se procura una figura efectiva en y por su acción, inscribiendo sus procedimientos efectivos en un horizonte que le permite intuir el lugar de su ser por venir. Sin embargo, la capacidad de la existencia de volverse efectiva es una "forma de vida", según la expresión de Wittgenstein. La perspectiva que habita la acción es, en los hechos, la búsqueda de un estado de cosas que sería equivalente a la fuente inspiradora de una cierta disposición concreta de la existencia, como respuesta a la idea de "existencia auténtica". La tradición filosófica ha construido, para expresar esta perspectiva, el concepto de "vida buena". Debemos inmediatamente precisar que la "vida buena" debe ser una vida "con otro". Lo que expresa la idea de "ser auténtico" es una condición de naturaleza muy general, independientemente de toda particularidad histórica, caracterizando al existente humano como tal y no a tal o cual grupo o a tal o cual tradición. Según el vocabulario tradicional se podría decir que esta condición es de tipo universal. In- 
dependiente de todo rasgo particular ella es a priori. Aunque la experiencia empírica nos enseña que existe en los hechos una pluralidad de existentes humanos y que lo que puede ser afirmado como a priori del existente humano vale inmediatamente para cada uno de los existentes reales, que son llamados a reconocerse mutuamente como "existente humanos".

La universalidad formal de lo a priori se traduce en la universalidad concreta de la humanidad efectiva. Como esta determinación es esencial, califica también como esencial la perspectiva de la vida buena, que expresa un a priori de la condición humana. Finalmente, es necesario reconocer inmediatamente que existe una pluralidad de seres humanos que construyen su vida en común a través de instituciones y que es por medio de la institución que la exigencia puede recibir sus determinaciones concretas. La consideración de estos tres elementos -perspectiva de un telos bajo la forma de la "vida buena", pluralidad de los existentes humanos, mediación de las institucionesconduce a la definición que Paul Ricoeur ha dado de la ética en su libro Soi-même comme un autre: la ética es "búsqueda de la 'vida buena' con y para el otro en instituciones justas" (2, p.202).

\section{La determinación de normas}

El término "ética" es a veces empleado como concepto de primer orden, para designar la conducta ética o la ética como práctica o aun la "vida ética" y, a veces, como concepto de segundo orden, para designar la reflexión desarrollada sobre la ética, en el sentido del primer orden. Podríamos denominar la ética entendida en este segundo sentido como "ética reflexiva". Dos tareas son confiadas a la ética reflexiva: la determinación de lo que es constitutivo de la ética y, en particular, la clarificación de lo que le da un carácter normativo, que le permite determinar normas que pueden elucidar la acción respecto de sus orientaciones.
Más arriba hemos intentado bosquejar una respuesta posible a la interrogante sobre lo constitutivo de la ética, conectando la dimensión ética de la acción a la estructura de la existencia. Esta aproximación de la temática nos procura una indicación sobre el fundamento de la normatividad de la ética: lo que confiere a las prescripciones éticas su carácter normativo es la presencia en la estructura de la existencia de una exigencia que toma la forma de una orientación sobre la "vida buena". Pero esta indicación es extremadamente resumida. La reflexión debe intentar, a lo menos, precisar cómo las normas con un contenido concreto podrían ser elaboradas.

Antes que nada conviene descartar posibles malentendidos. El término norma podría sugerir la idea de un procedimiento consistente en "aplicar una norma a una situación concreta". En tal perspectiva la norma debería ser capaz de poder reunirse directamente con la situación implicada y prescribir de manera casi automática lo que debe ser hecho o, al contrario, evitado. Sin embargo dicha concepción se inspira en un modelo que no es pertinente, de manera absoluta, cuando se trata de juzgar sobre la acción. Es el modelo de un programa operatorio orientado al comportamiento de un autómata: el programa indica, para cada estado posible del autómata, cual es la maniobra que debe ser ejecutada.

El registro de la acción, no puede ser reducido, de ninguna manera, al registro o nivel de una operación. Puesto que la operación es concebida como un proceso que se ejecuta de forma mecánica, según reglas establecidas, lo que la separa completamente de la significación (como la operación de una máquina que ejecuta una división sin saber que efectúa una división); la acción es un proceso que se ejecuta en el marco de una intención y que se guía de manera continua por lo que ésta sugiere, lo que esta significación incluso le impone. El programa operatorio es aplicable de manera indefinida y en este sentido es universalizable. La acción, al contrario, es siempre singular, puesto que a través de ella, en un momen- 
to de la trayectoria de la vida, se pone en juego la existencia, lo que supone la presencia del pasado y la apertura respecto de posibles que la acción permite bosquejar.

Esta singularidad de la acción instituye la singularidad de la situación puesto que a través de esta última resuenan en la existencia todos los condicionamientos que la afectan e implican para la existencia una significación que ningún análisis puede agotar. Ello determina también la singularidad de lo que se efectúa en la acción, puesto que el efecto que esta provoca no se reduce a las manifestaciones exteriores que se pueden observar, sino que se enuncian esencialmente a través de las significaciones que se manifiestan en la vida del agente. De esta manera, ni la situación, ni su efecto, pueden ser descritos como describimos las circunstancias de una operación y un procedimiento. Una y otra explicitan significaciones. Sólo podemos entenderlas a través de un procedimiento de tipo hermenéutico.

Lo que se puede esperar de una norma no es de prescribir una regla a una acción que le bastaría a ésta con seguir paso a paso, sino de ayudarla a orientarse en una situación que plantea problemas desde el punto de vista de una exigencia ética. De manera más precisa, es permitir ver lo que implica esta exigencia respecto de la orientación de la acción, en una situación específica. Tiene una función de mediación, entre una orientación de carácter fundamental y un estado de cosas en relación al que debe poder determinarse. Esta mediación no es completamente concreta, en el sentido que no conecta una acción determinada con una situación también determinada, sino que un tipo de acción con un tipo de situación. El papel de la norma es de volver presente en la acción, de alguna manera, lo que es constitutivo de la ética y de procurar el fundamento y la justificación a lo que prescribe. La norma no cumple esta exigencia por la capacidad de subsumir una proposición, describiendo la situación en una proposición que expresa la exigencia ética, sino por medio de una práctica interpretativa que permite ver la situación en la perspectiva de esta exigencia. El problema que se plantea a la ética reflexiva es: o bien volver explícita la justificación de normas existentes en la tradición ética o construir normas para situaciones inéditas, como es el caso de la bioética. Pero la justificación, en el caso de las normas que existen, consistirá en rehacer el camino que ha conducido a la formulación de normas aceptadas por la tradición. Así, en definitiva, el problema es, de un lado o del otro, la construcción de normas.

Se desprende del carácter mediador de la norma su capacidad de colocar al unísono un tipo de situación y un tipo de acción. Debe abarcar dos componentes descriptivos que permiten caracterizar un tipo de situación y un tipo de acción, proponiendo la síntesis, bajo la forma de una prescripción. La norma debe, por lo tanto, comprender un tercer elemento, un operador que exprese precisamente su capacidad de prescribir.

Una reflexión cuyo papel es explicitar el proceso que describimos debe poder manifestar claramente lo que funda la prescritividad de la norma, es decir, la exigencia ética. Kant ha formulado esta exigencia fundamental a través de lo que denomina la ley fundamental de la razón pura práctica:

Actúa de tal manera que la máxima de tu voluntad pueda valer siempre al mismo tiempo como principio de una legislación universal (3, p.30).

Esta ley impone a toda máxima de acción que se propone como principio ético, adoptar la forma de la universalidad. Ella tiene, por lo tanto, un carácter puramente formal. Pero establece adecuadamente que esta forma debe ser una "legislación", el concepto de "ley" aplicándose en este contexto al orden moral. Y la universalidad de la que se trata no es simplemente universalidad lógica, es la universalidad real de lo que Kant llama un "mundo moral", es decir, un orden en cual todas las prácticas que forman parte del contenido concreto de la vida serían conformes a la ley moral o 
aun, de una forma de vida que sería la realización efectiva de la "vida buena".

Que esta idea de una "legislación universal" se oriente, en un contexto kantiano, hacia una universalidad real aparece claramente en la segunda formulación que Kant da del principio supremo de la razón práctica, en la $\mathrm{Me}$ tafisica de las costumbres. Esta segunda formulación retoma la primera, pero colocándola explícitamente desde el punto de vista de la acción razonable. De manera general, la acción aborda su capacidad de generar efectos fijándose fines. Lo que caracteriza la acción como razonable es que ella se determina, en la elección de sus fines, de acuerdo a principios. Y, según el principio de la universalidad, ella es acción conforme a la exigencia ética, es decir, determinándose en conformidad con máximas universales y dándose por lo tanto fines con valores universales. Pero un fin de carácter universal no puede estar subordinado como medio a otros fines, puesto que corresponderían a visiones subjetivas, que tendrían por lo tanto sólo un valor particular, sin otro fundamento que la determinación subjetiva que los adopta. Para ser universal debe valer para todos los seres razonables.

El hecho de la existencia de una pluralidad de seres razonables introduce aquí una condición que transforma la universalidad formal en universalidad real. La existencia contiene en ella misma el deseo de reconciliarse con su ser auténtico. Podemos expresar esto diciendo que ella se concibe como teniendo la tarea de asumir realmente todo lo que condiciona su ser, cuyo estatuto es la autonomía. Lo que este estatuto le impone, de forma resumida, es reconciliarse consigo misma. Este estatuto y la condición que se desprende se realizan en los existentes concretos. El sentido concreto de la condición que impone a la existencia de reconciliarse consigo misma se precisa como la condición impuesta a la existencia de reconciliarse consigo misma en odos los existentes o aún más, como la condición impuesta a la existencia de reconocerse en todo momento.
El fin que se impone a la acción, en virtud del estatuto de la existencia, debe por lo tanto ser un fin válido para todo existente, según el vocabulario kantiano, para todo ser razonable. Debe por lo tanto ser independiente de todas las particularidades subjetivas, dicho de otro manera, debe tener un valor absoluto, aquel de "un fin en sí". Un fin aceptado como medio no podría por lo tanto tener valor ético más que en la medida que fuera condición necesaria de un fin en sí. Kant dice:

El hombre y, en general, todo ser razonable existe como fin en sí mismo y no simplemente como medio para cualesquier uso de ésta o aquella voluntad (4, p.148).

Esto nos conduce directamente a la célebre fórmula kantiana:

Actúa de tal manera que trates la humanidad, tanto en tu persona como en la de cualquier otro, al mismo tiempo y siempre como un fin, nunca simplemente como un medio (4, p.150).

Esta formulación del principio de base de la normatividad ética permite ver claramente su significación concreta. ¿Qué significa, concretamente, en las circunstancias de la vida real, tratar a otro como fin? Es claro que este principio por sí solo no permite la construcción de normas determinadas. Por eso es necesario comprenderlo como abriéndose hacia la perspectiva que permite que la acción pueda determinarse éticamente en las situaciones enfrentadas. Es de esta perspectiva que las normas obtienen su justificación. En este sentido es fundadora y como tal tiene el carácter de una condición última. No extrae su poder fundador de otro principio más fundamental, sino que de su estatuto semántico, que es ser la expresión de un hecho. Este hecho es la presencia en la existencia de la exigencia constitutiva que se traduce en la normatividad de las normas. En el contexto kantiano es la conciencia de la "ley fundamental de la razón pura 
práctica". Kant nos dice que ella es "un hecho (factum) de la razón puesto que no podrían extraerse por el razonamiento, de los datos anteriores de la razón, por ejemplo, de la conciencia de la libertad (puesto que esta conciencia no nos es dada primeramente) sino porque ella se nos impone por sí misma, como una proposición sintética a priori, que no está fundada en ninguna intuición (Anschauung), pura o empírica" (3, p.31). La afirmación que la ética es una dimensión de la existencia es posible porque su inscripción en la existencia se impone como un hecho sui generis, que no se relaciona con la percepción ni con las evidencias racionales, sino con una determinación constituyente.

Es esta misma realidad fáctica que encontramos en la base de la segunda formulación kantiana. Ella supone el reconocimiento de la pluralidad de los seres razonables. Se podría afirmar que se trata de un hecho empírico. Lo que es empírico es el hecho de la pluralidad de los individuos pertenecientes a la especie homo sapiens. Aunque se trata en particular de "seres razonables", es decir, capaces de actuar en función de principios y en una perspectiva de universalidad. Pero, si es posible hablar de seres razonables, es porque se reconoce en ellos la existencia del mismo hecho que está en la base del orden ético. Este reconocimiento no es de tipo empírico. Y el dato de la pluralidad, como precisión de la dimensión ética, tiene el mismo sentido. Su virtud es de permitir la transición de la universalidad formal a la universalidad concreta y, al mismo tiempo, asumir la pluralidad empírica -que tendría un sentido sólo biológico- como una pluralidad que se puede calificar de trascendental, que tiene un sentido ético.

La segunda formulación que da Kant del principio de base de la "razón práctica" define bien una perspectiva, aunque la reflexión ética debe ser capaz de dar a esta perspectiva un contenido concreto. Para ello es necesario identificar los contextos en los cuales tiene lugar la acción. Estos contextos son el resultado de diferentes condicionamientos que determinan de antemano los campos de posibilidad en los cuales la acción podrá situarse y, que al mismo tiempo, le procuran los medios sobre los cuales puede sostenerse para alcanzar los objetivos que se propone.

De manera muy general podemos distinguir cuatro tipos de condicionamiento: existen aquellos que se imponen por el entorno cósmico, aquellos inducidos por el desarrollo del universo técnico, los que provienen de las base biológicas de la existencia y los que se desprenden de las relaciones interhumanas. Cada una de estas categorías se encuentra mediatizada por dinámicas específicas: las dinámicas del entorno cósmico son aquellas que son descritas por las ciencias de la naturaleza, las dinámicas de la técnica son engendradas por el funcionamiento de los artefactos, las dinámicas biológicas se encuentran en la base de la formación y de las metamorfosis de las formas vivas y las dinámicas propias a las interacciones de los humanos son engendradas por el movimiento de la historia, la evolución de las culturas y la vida de las instituciones. Cada tipo de dinámica es un condicionamiento en la medida que impone límites y obligaciones a la acción: es parte de lo inevitable, que es, por otra parte, variable en el tiempo.

Pero también cada tipo de dinámica supone niveles diversos, zonas de indeterminación, respecto de las cuales la acción puede intervenir, alterando las finalidades intrínsecas de las dinámicas en el sentido de sus propias finalidades. La acción es siempre una iniciativa estructurada en función de objetivos y tratando de movilizar ciertos medios para concretizarlos. Puede ser calificada de racional cuando se preocupa de ajustar, de manera óptima, los medios disponibles con los fines, sin olvidar los límites que se imponen. Puede ser calificada de razonable cuando posiciona la acción, escoge sus fines y los medios necesarios, en un campo imantado por la "vida buena". Las condiciones de la racionalidad son objeto de una determinación de carácter científico. Las condiciones que permiten calificar la ación como "razonable" se relacionan con una her- 
menéutica de la acción. Es en el contexto de estas condiciones que se sitúa adecuadamente el problema de la construcción de normas.

La ética, como dice Paul Ricoeur en la fórmula reproducida más arriba, es esencialmente una intencionalidad, no un estado de cosas. La "vida buena", que es el objetivo de esta intención, se enuncia como un horizonte, pero horizonte que también se enuncia como instauración. Lo que se busca instaurar define una tarea confiada a la acción, lo que le confiere a ésta una responsabilidad particular. $\mathrm{La}$ instauración apuntada es equivalente a la saturación de la intencionalidad, es decir, la proyección efectiva de la vida humana, lo que la intención sólo representaba como la realización integral de la existencia. Pero la realidad de la vida humana es el resultado de condicionamientos que la conectan con el cosmos, en el flujo de la vida, en el universo de los artefactos, en la cultura, en la historia, en las instituciones. La tarea de la acción es que estos condicionamientos se conviertan en soportes de una coexistencia, que responda a la idea de lo que Kant denominaba "un mundo moral".

La acción posee en sí misma un poder de iniciativa que la vuelve capaz de darse tal o cual orientación. Es lo que resulta del estatuto de autonomía que pertenece a la existencia. La autonomía, considerada desde el punto de vista del individuo que actúa, es independencia respecto de las determinaciones exteriores, capacidad de decidir por sí mismo y a partir de sí mismo. La autonomía, considerada desde el punto de vista de su relación con las determinaciones exteriores, es, como lo dice Kant en la Crítica de la razón pura:

Una facultad de originar desde sí misma una serie de acontecimientos, de tal manera que en sí misma nada comienza, pero como condición incondicionada de todo acto voluntario, no sufre, en términos temporales, ninguna de las condiciones anteriores, a pesar que su efecto comienza en la serie de fenó- menos, pero sin poder constituir jamás un comienzo absolutamente primero (5, p.405).

Es la libertad como poder que vuelve la acción capaz de asumir la tarea que le es confiada. Es también este poder que se encuentra en el corazón de esta tarea. El desafío de la libertad es la libertad. Retomando una formula kantiana, podríamos decir que la razón práctica es el vigilante de sus propias leyes. A través de ello podría agregarse: vigilante de sí misma. De manera más simple se podría decir que lo que se juega en la acción es lo que constituye verdaderamente al ser humano, lo que lo singulariza y lo diferencia, en relación con toda la naturaleza, es, en resumen, la humanidad del ser humano. Esta calidad es dada al ser humano, pero como una exigencia que le corresponde asumir en su comportamiento efectivo, aunque permanece relativamente indeterminado. Es en el contacto con las situaciones concretas, en las cuales se encuentra situada la acción, que la existencia es conducida a descifrar parcialmente, paso a paso, esta indeterminación, descubriendo en la misma situación lo que ésta le exige y la manera como se enuncia la responsabilidad que se desprende de la humanidad del hombre. Se podría decir que en cada uno de estos procesos la acción debe enfrentar la exigencia de volver más explícita y manifiesta la humanidad del ser humano.

Lo que es solicitado a la acción no es siempre evidente $y$, en ciertas situaciones, francamente problemático. Es en ese momento que la razón práctica - gracias a su capacidad de juicio- es llamada a intervenir. El juicio contiene un componente de interpretación que trata de ver la situación desde el punto de vista de su relación con la exigencia ética y un componente voluntarista -que se pronuncia asumiendo los riesgos y peligros- sobre lo que le pide la conciencia ética en la situación interpretada. El juicio - conectando entre sí los dos componentes- efectúa una síntesis; es la manera como la conciencia ética pura se apropia de la 
situación, tal como ella es comprendida y como se problematiza para la conciencia ética. $\mathrm{O}$ aun, es la manera según la cual la conciencia ética pura es reflejada en el registro de la acción, en la medida que ésta es confrontada con una situación comprendida de forma específica.

En la estructura de la acción este tipo de juicio precede a la acción. Lo podemos observar en dos niveles. Existe el juicio que interviene inmediatamente antes de la decisión y gracias al cual el agente se determina a actuar de tal manera. Existe el juicio que evalúa solamente sobre la base de situaciones posibles y, por lo tanto, de situaciones esquematizadas que no tienen la determinación plena de una situación real. El juicio sólo puede concluir de manera esquemática, recomendando no un tipo de acción concreta sino que una estrategia de acción. Este tipo de juicio, a pesar de su relativa indeterminación, puede ser muy clarificador para la acción en el sentido que procura indicaciones reflexivas al juicio de primer tipo. Es este tipo de juicio esquemático que interviene en la construcción de normas.

De manera general podemos afirmar que construir una norma es efectuar la síntesis del juicio ético esquemático, que representa esquemáticamente la reacción de la conciencia ética respecto de la situación. Como la situación es el modo de inserción de la acción en los condicionamientos que la co-determinan, la norma que debe ser construida es de cierta manera la huella, en medio de estos condicionamientos, de la exigencia fundamental que habita la conciencia ética. Lo que se le pide al juicio es leer esta huella, es decir, comprender la situación como comprometiendo tal tipo de conducta.

La dimensión de la corporalidad, que es una de las dimensiones constitutivas del ser humano, figura entre los condicionamientos de la acción que la afectan de manera más profunda. De forma más precisa, se trata de condicionamientos que afectan la existencia a través de sus fundamentos biológicos. Podemos calificarlos de "somáticos". La problemática de la determinación de las normas en el con- texto de situaciones analizables en término de condicionamientos somáticos puede ser considerada como la problemática central de la bioética.

La dificultad particular de esta problemática es que pone en juego, de forma esencial, las relaciones entre lo que se llama "espíritu" y lo que se llama "cuerpo". A esta distinción corresponden dos manera de comprender y describir la realidad humana. Se la puede describir evocando operaciones y capacidades notables -como las operaciones intelectuales de la adquisición de conocimientos, de razonamiento, de intervención de manera general, respecto de lo que se llama "el pensamiento"o capacidades tales como el lenguaje, las pericias técnicas, la memoria, la anticipación o también y sobre todo, evocando las modalidades diversas a través de las cuales se manifiesta la apertura al otro como el diálogo, la cooperación, la generosidad, las formas infinitamente variadas de la simpatía, la amistad, el amor. Es al conjunto de estas operaciones, capacidades, comportamientos y las dinámicas que le son asociadas que apunta el término "espíritu". Pero también se puede describir la realidad humana, en la medida en que ella se inscribe en el movimiento general de la vida, en los términos que pone a nuestra disposición el lenguaje de la ciencia biológica. Se puede intentar "reducir" las operaciones y capacidades características del "espíritu" a procesos analizables en términos de funcionamiento somático. Se puede también intentar mostrar su irreductibilidad a condiciones de orden somático, corriendo el riesgo de un dualismo radical.

Sin embargo, existe una unidad del ser humano, cuya comprensión adecuada debe, a lo menos, tenerla presente, incluso si no puede explicarlo. No se puede evitar una dualidad de descripciones. Podemos incluso hablar de una pluralidad de descripciones, por ejemplo, agregando a los dos niveles tradicionales de descripción un nivel correspondiente al dominio de los fenómenos de orden psíquico. En todo caso, existe una resonancia de cada componente de la realidad humana sobre todas las 
otras. Y existe siempre una reinterpretación posible de un tipo de descripción en otro.

Así acontece con este aspecto de la realidad humana que es designado por el término "cuerpo". La fenomenología introdujo una distinción muy clarificadora entre el "cuerpo-objeto" y el "cuerpo-sujeto" o "cuerpo-vivido". El cuerpo-objeto es el cuerpo visto desde el exterior y analizable por los métodos de la ciencia biológica e incluso de las ciencias de la naturaleza en general. La descripción en esta perspectiva tiene el gran mérito de instruirnos sobre la participación de la realidad humana en la realidad cósmica, lo que explicita la relación estrecha que conecta los condicionamientos biológicos a los condicionamientos cósmicos. El cuerpo-sujeto, por otra parte, es el cuerpo tal como es vivido, sentido, ejercido, el cuerpo como medio entre la vida subjetiva y el mundo en el cual se encuentra inmerso. Es el cuerpo que siente, sufre, goza, que resuena frente al rumor del mundo, es también el cuerpo que actúa, que se expresa libremente como en el baile, como juego en el deporte, que se construye un mundo de artefactos en los cuales se proyecta de cierta manera. La fenomenología ha elaborado un lenguaje que nos permite describir el cuerpo-sujeto como tal. Pero lo que ella ha mostrado esencialmente, es que el concepto de cuerpo debe ser interpretado a partir del concepto de existencia. El cuerpo no es un instrumento al servicio de una dinámica existencial puramente espiritual, ni una entidad biológica simplemente adherida al espíritu; el cuerpo no existe fuera de la existencia o, de forma más radical, es la visibilidad de la existencia. Es su presencia en el espacio y el tiempo.

Dada esta unidad del ser humano, existe un condicionamiento recíproco entre el cuerpo-objeto y el cuerpo-sujeto. De esto es posible concluir que toda modificación del cuerpo-objeto tiene consecuencias sobre el cuerpo-sujeto y por consecuencia, sobre la misma existencia. Es posible pensar que esta consecuencia es tanto más intensa puesto que la modificación inducida se relaciona con ca- pas más profundas de la organización somática del cuerpo-objeto. La biología contemporánea ha logrado conducir su análisis al nivel de los genes y desde allí, al nivel de las determinaciones químicas, cuyas dinámicas sostienen el funcionamiento global de lo vivo. El acceder a niveles profundos de la organización somática ha permitido intervenciones reguladas según determinados planes, desarrollando eficazmente determinados objetivos que no son necesariamente los mismos que las finalidades inscritas en los procesos vitales "naturales".

De esta manera se han creado situaciones que son inéditas y que constituyen desafíos para el juicio ético. La dificultad principal en este nuevo contexto, en lo que se relaciona con la construcción de normas es, la adecuada comprensión de las situaciones "artificiales". No se puede tener una comprensión adecuada limitándose a examinar las consecuencias de las intervenciones posibles en los términos que aparecen apropiados para el estudio del cuerpo-objeto. Si estas situaciones plantean problema es en relación con el cuerpo-sujeto, lo que constituye un procedimiento de tipo hermenéutico y no de tipo analítico. La reflexión sobre la construcción de normas pasa por la elaboración de una metodología hermenéutica de las situaciones.

La función de la norma es ayudar a la acción a asumir las posibilidades ofrecidas, en función de imperativos, positivos o negativos $\mathrm{o}$, al menos, en función de recomendaciones positivas o negativas. Al juicio ético le pertenece procurar a la acción las prescripciones que podrán guiar las decisiones. Pero la situación aporta su contribución a esta determinación, en la medida que presenta posibilidades a partir de las cuales la acción debe elaborar las estrategias apropiadas.

Una estrategia apropiada es aquella que puede inscribirse en la dirección constitutiva de la ética. Para satisfacer su tarea el juicio ético debe poder leer en la situación cuál es la estrategia apropiada. La comprensión 
de la situación debe poder conducir el juicio hacia el reconocimiento de lo que en la situación es exigido a la acción. Para dicha comprensión el juicio ético debe poder instalar en lo buscado por la ética, por medio del pensamiento, las posibilidades ofrecidas por la situación. Debe poder pesar y evaluar estos posibles, considerándolos desde el punto de vista de su incidencia posible, sea negativa o positiva, sobre la vida ética. Se podría formular esta condición introduciendo la idea de integridad. La tarea del juicio ético es de comprender la situación y los posibles que ella contiene desde el punto de vista de su relación con la integridad de la existencia. Y puesto que en la bioética la existencia es puesta en juego a través de sus condicionamientos biológicos, la determinación de normas toma la forma de una determinación de estrategias posibles, en la perspectiva de lo que puede esperarse razonablemente en función de los efectos somáticos. El juicio será conducido a recomendar-incluso a imponer- las estrategias que parezcan susceptibles de contribuir a la integridad de la existencia y desaconsejar -incluso prohibirlas estrategias que parezcan susceptibles de poner en peligro esta integridad.

\section{Los procedimientos concretos de la bioética}

Como se ha subrayado, las normas apuntan hacia una generalidad al menos relativa, es decir, tienen un carácter esquemático: conectan tipos de situaciones a tipos de acciones. En sus procedimientos concretos, que se relacionan con situaciones reales y acciones efectivas, la bioética tendrá que elucidar la acción desde el punto de vista de su valor ético, pronunciándose sobre las posibilidades que presenta la situación. Deberá, por lo tanto, elaborar juicios -como en el caso de la determinación de normas- pero esta vez relativamente respecto de las circunstancias singulares. Ella podrá sostenerse en normas disponibles que le parezcan pertinentes respecto de la situación, pero le corresponderá franquear la distancia que separa el esquematismo de la realidad efectiva de una situación.

El juicio ético que se encuentra en la base de las normas invocadas deberá ser completado por un juicio ético, que deberá apreciar el grado de pertinencia de las normas evocadas y agregar a lo que ellas prescriben lo que permanecía indeterminado en su formulación. En estos dos procedimientos el juicio ético deberá pronunciarse sobre la manera como la situación, considerada concretamente, deberá ser apreciada desde el punto de vista de los objetivos de la ética. En la consecución de este objetivo deberá hacer intervenir a la intuición. Esta intuición será sostenida por el trabajo hermenéutico supuesto por la determinación de normas retenidas como pertinentes. Por otra parte, en situaciones donde los datos para las normas son demasiado indecisos, el juicio será llamado a aproximarse a la situación concreta, tomando posición a partir de sí mismo, de manera voluntarista, justificándose eventualmente a través de la referencia a normas prudenciales, que aconsejan seguir el camino más seguro, a pesar de que esta decisión no sea evidente.

Como la intervención de la intuición y de la voluntad corren el riesgo de no tener por sí mismas la seguridad suficiente, será generalmente oportuno someterlas a apreciaciones entrecruzadas, utilizando la contribución de disciplinas y experiencias diferentes. Esto abre una perspectiva en dirección de los consejos de ética y anuncia la problemática de la institucionalización de la ética.

Deberíamos limitarnos aquí con evocarla. Sin embargo, independientemente de los procedimientos institucionalizados, - a través de los cuales se forma el juicio ético y se preparan decisiones fundadas en la razón-se ve claramente que tanto en la construcción de normas como en el juicio que orienta directamente la decisión, la interpretación representa un papel esencial. La ética es fundamentalmente una exigencia, pero ésta se deja ver en situaciones concretas. La cuestión central planteada se refiere a la significación de estas situa- 
ciones en relación con esta exigencia. Es la cuestión que debe encontrar el juicio ético, como hemos intentado mostrarlo más arriba. Sin embargo, nos encontramos aquí con la perspectiva de la tecnociencia. Es la tecnociencia que provoca situaciones nuevas, que vuelven perpleja la conciencia ética y que generan -por reacción- una formidable reactivación de la preocupación ética en la cultura contemporánea. Pero la tecnociencia, como se ha dicho, se sostiene sobre una cierta visión del mundo, que se vuelve creíble por sus éxitos y que constituye una parrilla de lectura de la realidad en su totalidad. En lo que respecta a la bioética, la realidad tratada se refiere a las bases biológicas de la existencia. La exploración de esta realidad es uno de los dominios de intervención de la tecnociencia y procura una descripción profunda en el contexto de su propio lenguaje. Se podría decir que esta descripción permite asociar a toda situación, encontrada por la acción en este dominio, una interpretación "objetiva". Es la interpretación que da la comprensión del cuerpo-objeto.

Esta descripción no procura por sí misma, al menos directamente, ninguna indicación relativa a la dimensión ética de la existencia, por la simple razón que las decisiones que se encuentran en la base de la tecnociencia han puesto entre paréntesis e instituido un mundo técnico-científico, cerrado sobre sí mismo y de cierta manera indiferente a la resonancia vivida de sus propias instauraciones. Una situación sólo puede ser juzgada éticamente en la medida que contiene en sí misma un aspecto a través del cual se pone en juego la dimensión ética de la existencia. Se podría decir que este aspecto constituye el momento ético de la situación. Es por ello que permite un juicio ético. Lo es también por su contribución al destino ético de la existencia.

Se podría llamar esta significación inducida por la ética en la situación, su "significación ética". Sin embargo, no se puede manifestar una significación ética de una significación objetiva, por la razón que esta última no contiene nada, incluso al estado implícito, que podría orientarse en la dirección de su significación ética. La significación ética de una significación es la resonancia de esta significación sobre la existencia considerada en su totalidad, con su historia y todas sus dimensiones. Ella es el aporte, positivo o negativo, de la situación a la calidad ética del existente. Sólo existe significación ética en una situación que introduce por sí misma una relación entre su contenido propio y la existencia en su totalidad. Tal significación es el sentido que puede tener la situación para los existentes que viven y este sentido es el sentido que puede tener la situación para los existentes que la viven y, este sentido, es la manera como esta situación se inscribe en el movimiento de la existencia. Esta inscripción comporta en particular la resonancia que puede tener sobre el cuerpo-sujeto. Se puede llamar a esta significación, la "significación existencial" de la situación. La significación ética de una situación supone que ésta posee una significación existencial y depende del contenido de ésta.

La tarea del juicio ético es apreciar, frente a una situación dada, cuál es la estrategia de acción que es exigida -en el contexto de esta situación- a través del llamado que la dimensión ética de la existencia dirige al existente humano. Consiste en leer, al nivel de la situación, lo que la conciencia ética exige a la acción. Una lectura consiste en desprender la significación ética de la acción, aunque la explicitación de esta significación supone la previa puesta al día de la significación esencial de la acción. Es necesario agregar que la comprensión de la situación desde el punto de vista de su significación esencial debe tomar en cuenta, para ser pertinente, su significación objetiva. Se podría decir que la significación existencial es el sentido que toma para la existencia en totalidad la significación objetiva que el lenguaje técnico-científico le ha atribuido. 
La estructura según la cual se articulan estos diferentes niveles de significación determina la organización interna de la hermenéutica ética. La puesta en juego de esta estructura, que es el resultado de la deliberación, clarifica la acción, pero ello es sólo el prolegómeno. La acción deviene acción verdadera en el momento de la decisión. Ella se realiza en el esfuerzo sostenido a través del cual permite plasmarse en la realidad lo anticipado por la decisión. El mérito de la ética reflexiva, a la cual pertenece la bioética, es de colocar la vida ética bajo la égida de lo razonable, de lo que Kant denomina "la razón práctica". Es también de recordarnos que esta razón es a la vez comprensión y compromiso y que ella es, en definitiva, el querer la instauración de lo humano en la humanidad.

\section{Referencias}

1. Carnap R. Testability and Meaning. Philosophy of Science 1936; 1:420-71.

2. Ricoeur P. Soi-même comme un autre. Paris: Editions du Seuil; 1990.

3. Kant E. Critique de la raison pratique. Paris: Presses Universitaires de France; 1960.

4. Kant E. Fondements de la métaphysique des moeurs. Paris: Librairie Delagrave; 1960.

5. Kant E. Critique de la raison pure. Paris: Universitaires de France;1944. 